\section{Flower Color Preferences of Western Flower Thrips}

\author{
Meredith R. Blumthal ${ }^{1}$, Raymond A. Cloyd ${ }^{2}$, L. Art Spomer ${ }^{1}$, \\ and Daniel F. Warnock ${ }^{1}$
}

ADDITIONAL INDEX WORDs. floriculture, flower spectral reflectance, Frankliniella occidentalis, greenhouse crops, integrated pest management, Thripidae, Thysanoptera, trap crops

SUMMARY. Flower color preference of western flower thrips [WFT (Frankliniella occidentalis ) (Thysanoptera: Thripidae)] was assessed by observing insect location after introduction into chambers containing four different colored flowers of each of three plant species: transvaal daisy (Gerbera jamesonii), matsumoto aster (Callistephus chinensis), and chrysanthemum (Dendranthema $\times$ grandiflorum). Preference was based on the number of WFT adults found on each flower 72 hours after infestation. Significantly higher numbers of WFT were found on yellow transvaal daisy and yellow chrysanthemum. When these accessions were compared in a subsequent experiment, WFT displayed a significant greater preference for the yellow transvaal daisy. Visible and near infrared reflectance spectra of the flowers used in the study were measured to determine the presence of distinct spectral features that would account for the relative attractiveness of the flowers. Likewise, the reflectance spectra of three commercially available sticky cards (blue, yellow, and yellow with a grid pattern) that are used to trap or sample for WFT were compared to those of the flowers to determine any shared spectral features that would support observed WFT flower color preference. The observed similarity between the yellow transvaal daisy and yellow sticky card reflectance spectra supports the hypothesis that flower color contributes to attractiveness of WFT. In particular, the wavelengths corresponding to green-yellow (500 to $600 \mathrm{~nm}$ ) seem to be responsible for attracting WFT. These findings also indicate that yellow sticky cards may be more appropriate in sampling for WFT than blue sticky cards. Although further research is needed, under the conditions of this study, yellow transvaal daisy appears to be a potentially useful trap crop for WFT.

$\mathrm{W}$ estern flower thrips is a major, worldwide arthropod pest of greenhouse crops (Daughtrey et al., 1997; Parrella, 1995). Western flower thrips damages plants by feeding on leaves and flowers (Higgins, 1992; Hunter and Ullman, 1992; Jan de Kogel et al., 1998) and vectoring the tospoviruses, impatiens necrotic spot virus, and tomato spotted

$\overline{\text { Acknowledgments.We thank Amy Dickinson, Theresa }}$ Meers, and Lesely Deem for their technical assistance. Research experiments were conducted in the laboratories of Michael Irwin, University of Illinois, Champaign-Urbana. Thomas Costamagna from University of California at Davis supplied western flower thrips. This research was made possible by a grant from the UIUC Campus Research Board (RES BRD CLOYD R 1-2-68037) awarded to Raymond A. Cloyd and Daniel F. Warnock. We also thank Jack Juvik, Department of Natural Resources and Environmental Sciences, University of Illinois, Champaign-Urbana, for his valuable contribution in critically reviewing the manuscript.

${ }^{1}$ Department of Natural Resources and Environmental Sciences, University of Illinois, 1201 S. Dorner Drive, Urbana, IL 61801.

${ }^{2}$ Department of Natural Resources and Environmental Sciences, University of Illinois, 1101 West Peabody Drive, Urbana, IL 61801 . wilt virus (Allen and Broadbent, 1986; Daughtrey et al., 1997; DeAngelis et al., 1994). The damage caused by WFT significantly reduces crop marketability (Parrella, 1995).

Western flower thrips control in greenhouses employs an integrated pest management program, which consists of scouting, insecticide applications, and biological control (Immaraju et al., 1992; Jacobson, 1995; Pearsall and Meyers, 2000; Shipp and Zariffa, 1991; Suderland et al., 1992). Control ofWFT might be improved with the use of trap crops grown in close proximity to the main crop (Javaid and Joshi, 1995). Most insects tend to exhibit a preference for certain plant species, cultivars, or crop growth stages (Hokkanen, 1991; Javaid and Joshi, 1995). The supposition in this concept is that the trap crops are more attractive to plant-feeding insects, including WFT, than the main crops and thereby distract the pest from locating the main crop, resulting in less damage and/or concentrating them into a localized site where they can be more effectively controlled (Hooper et al., 1999; Mills and Daane, 2005). This insect control strategy has been recognized for centuries and is still exploited in many agricultural cropping systems (Hokkanen, 1991). However, little is known regarding specific use of trap crops for control of WFT.

Western flower thrips are known to be attracted to certain flower colors and species (Vernon and Gillespie, 1990; Walker, 1974). Studies on the visual response of WFT have concentrated on specific colored surfaces with the goal of developing traps for monitoring populations (Brodsgaard, 1989; Chang-Chi et al., 2000; Cho et al., 1995; Gillespie and Vernon, 1990; Mateus and Mexia, 1995; Matteson et al., 1992; Moffit, 1964; Vernon and Gillespie, 1990, 1995; Yudin et al., 1987). Behavioral studies of WFT color preference (Gillespie and Vernon, 1990; Matteson et al., 1992; Moffit, 1964; Vernon and Gillespie, 1990; Yudin et al., 1987) have provided extensive yet variable results, with generally higher numbers of WFT captured on white, blue, blue-violet, and yellow traps (Mateus and Mexia, 1995; Matteson et al., 1992). However, these studies did not consider the spectral qualities of the colored surfaces, which may have influenced WFT preference.

Various factors determine the attractiveness of a plant to WFT, probably the most important of which are volatiles emitted from flowers (Bennison et al., 1999; Hooper et al., 1999; Teulon et al., 1993; ) and flower color (Chyzik et al., 1995; Kirk, 1997; Yudin et al.,

\begin{tabular}{llll}
\hline $\begin{array}{l}\text { Units } \\
\text { To convert U.S. to SI, } \\
\text { multiply by }\end{array}$ & U.S. unit & SI unit & $\begin{array}{l}\text { To convert SI to U.S., } \\
\text { multiply by }\end{array}$ \\
\hline 29.5735 & $\mathrm{fl} \mathrm{oz}$ & $\mathrm{mL}$ & 0.0338 \\
0.3048 & $\mathrm{ft}$ & $\mathrm{m}$ & 3.2808 \\
2.5400 & inch $(\mathrm{es})$ & $\mathrm{cm}$ & 0.3937 \\
25.4000 & inch $(\mathrm{es})$ & $\mathrm{mm}$ & 0.0394 \\
7.4892 & $\mathrm{Oz} / \mathrm{gal}$ & $\mathrm{g} \cdot \mathrm{L}^{-1}$ & 0.1335 \\
$\left({ }^{\circ} \mathrm{F}-32\right) \div 1.8$ & ${ }^{\circ} \mathrm{F}$ & ${ }^{\circ} \mathrm{C}$ & $\left(1.8 \times{ }^{\circ} \mathrm{C}\right)+32$
\end{tabular}


1987) because both act as host plant selection cues or stimuli over distance without requiring physical contact, with color typically more important at shorter distances. For example, flowering verbena (Verbena $\times$ bybrida) plants were found to attract WFT away from ivy geranium (Pelargonium peltatum) and chrysanthemum (Dendranthema spp.) (Hooper et al. 1999). The appearance of color is significantly influenced by surface properties; however, this is dependent on more than just the spectral characteristics of the surface (Hunter and Harold, 1987). Flower volatiles may be more responsible than color for WFT preferences in some cases (Teulon et al., 1993). However, quantitatively determining the effects of volatiles emitted from flowers on WFT behavior is more difficult than assessing the effects of color due to temporal and spatial factors (Terry, 1997). Most of the color preference information is not based on actual flower colors but on colored surfaces relative to sticky cards (Brodsgaard, 1989; Chang-Chi et al., 2000; Cho et al, 1995; Vernon and Gillespie, 1995) with WFT most attracted to white, blue, and yellow sticky cards (Terry, 1997).

The color visual sensitivity of WFT or why they seem to be attracted to certain colors and not others is not well documented. Many insects, including greenhouse whitefly (Trialeurodes vaporariorum) (Lloyd, 1921; MacDowell, 1972; Mound, 1962), bumblebees (Bombus spp.) (Gross and Carpenter, 1991), vegetable leafminer (Liriomyza sativae) (Chandler, 1981; Tyron et al., 1980), and WFT (Cho et al., 1995) are attracted to yellow-colored surfaces. However, these observations may be limited in terms of identifying trap crops because they were from studies using colored sticky cards or painted surfaces-not of plant origin.

Results from studies using live plants have been variable primarily due to the plant species tested. For example, Guam and Pringle (1994) observed that adult WFT sometimes preferred yellow roses (Rosa spp.) to other colors, whereas Chyzik et al. (1995) found WFT to be more numerous on violet flowers of gladiolus (Gladiolus spp.) followed by rose, yellow, white, red, and orange. More importantly, the specific spectral reflectance of the test flowers was not measured to confirm the preference for color or some other flower attribute. What humans perceive as identical colors are probably not identical (Cohen, 1988; Hunter and Harold, 1987) and most likely WFT has an entirely different visual response than humans. Overall, the primary method for selecting trap crops is still mostly trial and error.

The intent of this study was to determine if WFT had a flower color preference that could potentially be used in the selection of a trap crop to facilitate control and determine if this color preference was consistent across plant species. The best approach to finding the color or colors most attractive to WFT would be to start with the colors to which WFT are most visually sensitive. However, the photo-spectral sensitivity of WFT is not well documented. So, a more empirical approach was used where WFT were exposed to a selection of flower colors to determine which color, if any, they prefer. A further objective was to ascertain if WFT respond to specific wavelengths or combinations of wavelengths based upon plant spectral reflectance. Such information could be useful in selecting more effective trap crops, sticky cards, or other control methods.

\section{Materials and methods}

Western flower thrips were exposed to a selection of flower colors under controlled environmental conditions to determine what color or colors, if any, they prefer. This study was designed to assess if flower color is a potentially useful criterion to use in the development of trap crops for WFT control in greenhouses. Preference was evaluated based on the relative numbers ofWFT adults collected from each flower after $72 \mathrm{~h}$. The spectral reflectance of the flowers was measured to determine if the observed WFT preference, based on the number of WFT per flower, could be attributed to a response to specific wavelengths or combination of wavelengths. In addition, the spectral reflectance of three colored sticky cards was assessed.

ExPERIMENTAL SET-up. Clear plexiglas observation chambers $(44 \mathrm{~cm}$ long $\times 44 \mathrm{~cm}$ wide $\times 80 \mathrm{~cm}$ tall) with three $12-\mathrm{cm}$ diameter circular ventilation holes on three sides fitted with thrips screen $(135 \mu \mathrm{m})$ were used in the experiments (Fig. 1). Chambers were located in each of two identical walkin controlled environmental rooms

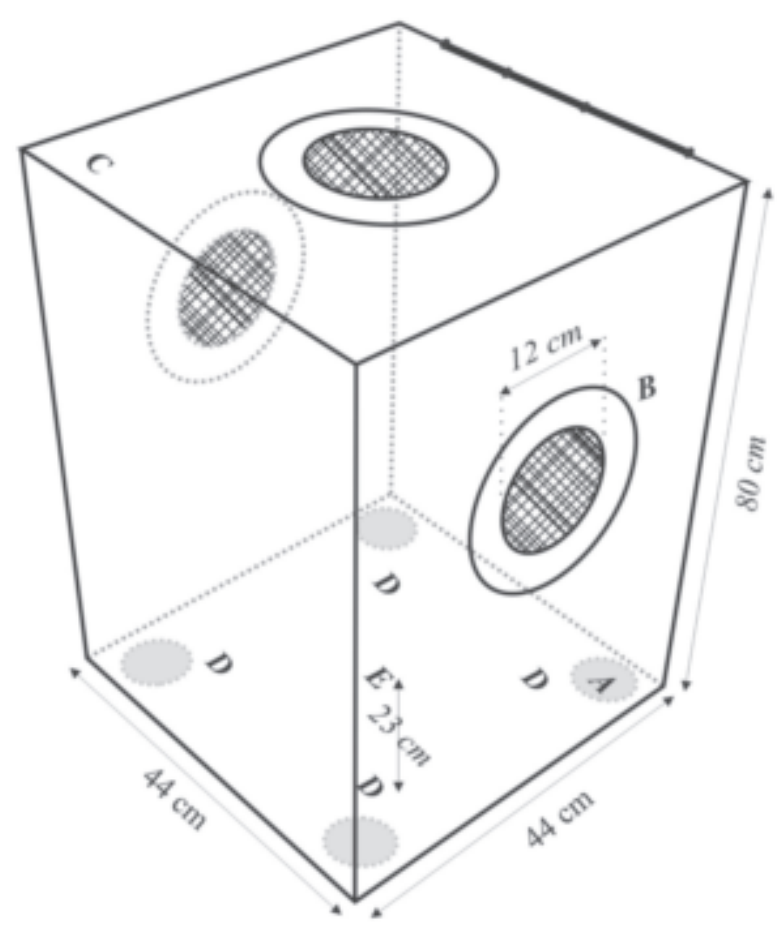

Fig. 1. Diagram of the experimental insect observation chamber constructed from $4.7-\mathrm{mm}$-thick $(0.185$ inch) clear plexiglas. (A) Protective pads on the bottom outside surface; $(B)$ ventilation holes covered with thrips screen $(135 \mu \mathrm{m})$; (C) hinged chamber top door; (D) location of the flower containers; and (E) location of the western flower thrips container at the center of the chamber ( 1 $\mathrm{cm}=0.3937$ inch). 
(approximately $3 \mathrm{~m}$ long $\times 1 \mathrm{~m}$ wide $\times 2 \mathrm{~m}$ tall) with a temperature of $24 \pm$ $3{ }^{\circ} \mathrm{C}$. The chambers were supported on an open bench approximately 3 $\mathrm{cm}$ above the floor. Room ventilation and temperature control was supplied from a heat exchanger located in the center of the ceiling and two 10 -inchdiameter fans drawing air through the heat exchanger and directing the air through a filter downward into the room. Treatments, which consisted of a chamber containing test flowers and adult WFT, were provided with a 14-h light/10-h dark photoperiod at 7-12 $\mathrm{mol} \cdot \mathrm{cm}^{-2} \cdot \mathrm{s}^{-1}$ diffuse irradiance in a 400- to $700-\mathrm{nm}$ bandwidth at the flower height by four $122-\mathrm{cm}$ T6 lite white fluorescent lamps paired in two shoplight fixtures centered $28 \mathrm{~cm}$ above the chambers. A covered glass $\operatorname{vial}(22 \mathrm{~mL})$ containing 200 adult WFT (mixed ages and sex) was placed in the center of the observation chamber and four jars containing the individual test flowers (described below) were placed equidistant (approximately $23 \mathrm{~cm}$ ) from the vial, each along one of the axes through the vial containing WFT and the corners of the chamber (Fig. 1). The flower stems were inserted through a $1-\mathrm{cm}$-diameter hole in a plastic lid covering a 106-mL baby food jar containing $100 \mathrm{~mL}$ of a $10-\mathrm{g} \cdot \mathrm{L}^{-1}$ floral preservative solution (Floralife, Waterboro, S.C.). Each stem was fully inserted through the jar lid until the flower heads were resting on top of the jar lid (Fig. 2). This ensured that all flowers were displayed at the same height and orientation in the chambers. After all the jars were in place, the vial containing adult WFT was opened and the chamber cage door was closed, then sealed with tape to prevent WFT adults from escaping during the experiments.

Flowers. The test flowers included four different colors of each of transvaal daisy, matsumoto aster, and chrysanthemum, all from the Asteracae family. Transvaal daisy colors tested were yellow ('Onedin'), orange ('Sunset'), red ('Monte Cristo'), and magenta ('Temptation'). The matsumoto aster flower colors were white, purple, pink, and magenta. Chrysanthemum flower colors were yellow, burgundy, white, and lavender. The matsumoto and chrysanthemum cultivars were unknown. These plant species were chosen because of their availability year around, availability in a variety of flower colors, and similarity in gross flower morphology. The total surface area of a sample of individual flowers was measured with a $\mathrm{Li}$-Cor LI-3100 area meter (Li-Cor, Lincoln, Nebr.) to ensure the flower surface area exposed to the WFT was similar among the different plant species for Expt. 2. From these measurements, it was determined that three chrysanthemum flowers and five matsumoto aster flowers were equivalent to one transvaal daisy flower. Shipments of the flowers were provided weekly from two wholesale florists (Bill Doran, Bloomington, Ill.; and Four Seasons, Litchfield, Ill.). Spray records from the commercial greenhouses where the flowers were produced indicated that no pesticides had been applied 2 weeks prior to harvest. Fresh flowers were used for each experiment, with one weekly order supplying enough flowers for two replications. The flowers were handled according to accepted guidelines for commercial florists (Biondo and Noland, 2000). Upon arrival, 3 to $5 \mathrm{~cm}$ of each flower stem was excised and the remaining portion of the flower stem was placed in a $11 \mathrm{~g} \cdot \mathrm{L}^{-1}$ flower preservative solu-

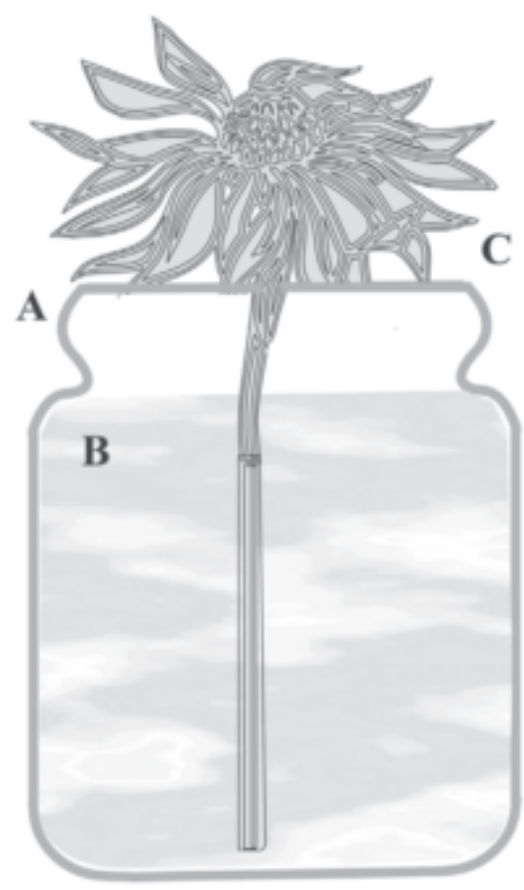

Fig. 2. Diagram demonstrating the position of the flowers in their individual containers. (A) Is a $160-\mathrm{mL}$ ( $5.4 \mathrm{fl} \mathrm{oz})$ covered flower jar; (B) is the floral preservative solution; and (C) is a flower with the stem inserted through the cover into the solution. tion and stored in a walk-in cooler (4 $\pm 2{ }^{\circ} \mathrm{C}$ ) with continuous illumination from cool white florescent lighting $\left(5-7 \mu \mathrm{mol} \cdot \mathrm{cm}^{-2} \cdot \mathrm{s}^{-1}\right)$ until used in the experiments. Flowers were visually examined for the presence of thrips prior to conducting the experiments. The flowers were removed from the cooler, placed into the jars, and allowed to acclimate in a laboratory $(24 \pm 2$ ${ }^{\circ} \mathrm{C}$ ) for approximately 15 to $20 \mathrm{~min}$ before they were positioned into the chambers.

Thrips. Western flower thrips used for both experiments came from two sources; one from a colony maintained on site at the University of Illinois Plant Care Facility, Urbana, and the other from a colony maintained at the University of California, Davis. The Illinois colony ofWFT was maintained as reported in Loughner et al. (2005). The California WFT colony was reared in mason jars covered with thrips screen ( $135 \mu \mathrm{m})$ under laboratory conditions of $24 \pm 5{ }^{\circ} \mathrm{C}$ and $50 \%$ to $75 \%$ relative humidity $(\mathrm{RH})$, and illuminated with high-intensity discharge (HID) lamps (a combination of 1000-W high-pressure sodium and metal halide). Fresh green bean pods (Phaseolus spp.) were provided as a food source for the colony. The California WFT was shipped overnight via carrier in special shipping containers to ensure their viability upon arrival. The shipping containers were comprised of a protective cardboard box $(28 \mathrm{~cm}$ long $\times 23 \mathrm{~cm}$ wide $\times 28$ $\mathrm{cm}$ tall) in which a styrofoam carton was inserted containing a frozen gel pack so that the contents remained at a cool temperature. In addition, a layer of cardboard separating the contents from the foam holders protected five $22-\mathrm{mL}$ glass liquid scintillation vials (Research Products International Corp., Mt. Prospect, Ill.) containing the adult WFT. The vials were sealed with porous foam stoppers to avoid asphyxiation of the WFT during transit. Shipments always arrived between 0930 and $1100 \mathrm{HR}$. Upon arrival, vials were immediately removed from the shipping container, and the WFT were allowed to acclimate under a laboratory fume hood for approximately 30 to $45 \mathrm{~min}$. After the WFT became visibly active, they were placed on a white sheet of paper $(20 \mathrm{~cm}$ long $\times$ $28 \mathrm{~cm}$ wide), collected and counted into a vial $(22 \mathrm{~mL})$ using a modified aspirator (Cloyd et al., 2001), and then used for each experiment. Because we 
were not able to obtain enough WFT from one colony, WFT used for the experiments were a mixture of the Illinois and California colonies with a majority $(75 \%)$ of the WFT procured from the Illinois colony.

Experiments. Two different experiments were conducted. Expt. 1 evaluated color preference using four different colors within a plant species. Expt. 2 identified the most preferred flower color/species overall using the colors that had the highest number of WFT of the three plant species that were evaluated in Expt. 1. To maintain the same geometric pattern between the WFT adults and flower containers as in Expt. 1, a white plastic flower, similar in morphology and surface area to the other flowers, was added to the chamber in Expt. 2. A replication consisted of one chamber, four flowers, and one vial containing 200 WFT adults (mixed ages and sex). In each experiment, the vial containing the adult WFT was opened and the chamber door immediately sealed. All the experiments were conducted at approximately the same time each day. After $72 \mathrm{~h}$, the chambers were opened and each flower was immediately inserted into a self-sealing plastic bag and taken to a laboratory for WFT collection and counting. The number of adult WFT per flower was determined by collecting them from the flower and bag surfaces using a vacuum aspirator collection device (Cloyd et al., 2001). Flowers were then emasculated after the collection process to ensure maximum efficiency of recovering WFT adults. The experimental chambers were thoroughly inspected for the presence of WFT and then cleaned after each replication to prevent possible residual WFT contamination in succeeding experiments. Expt. I was set up as a split-plot design (Steel et al., 1997) due to the two levels of randomization-plant species for each chamber, and flower color within each chamber. Expt. I was blocked over time with two replications per week conducted over 5 weeks, for a total of 10 replications. Expt. 2 was set up as a randomized complete-block design. There were two blocks with five replications in each for a total of 10 replications. Each set of replications was conducted over a 72-h period.

SPeCTrAL Properties. The reflectance spectrum of each of the treatment flowers was measured over a 300 to
$850 \pm 1 \mathrm{~nm}$ bandwidth with a Li-Cor LI-1800 portable spectroradiometer and LI-1800-12 integrating sphere. A custom sample holder was used so that two to three overlapping petals completely covered the integrating sphere sample port. This ensured that the spectroradiometer was measuring only flower petal color. Measurements were conducted in a darkroom in order to avoid extraneous light leakage into the sphere during the scans. The reflectance spectra of 10 petals were scanned per flower with five scans taken from the top and five scans from the bottom of each flower. These values were then averaged for a final number per flower. A similar procedure was used to measure the colored sticky cards for comparison with the flowers. The sticky card colors were blue, yellow, and yellow with a black-lined grid pattern. All three are commercially available from greenhouse supply companies such as Hummert International (Earth City, Mo.) and Whitmire Micro-Gen (St. Louis).

Statistical analysis. Data from both experiments were evaluated for normality and homogeneity of variances using SAS (version 8.0 for Windows; SAS Institute, Cary, N.C.). Normality criteria were not met, and so the data were transformed using a square-root transformation, which improved distribution of the data, meeting the criteria for normality and homogeneity of variances based on the residuals. Data for Expt. I were subject to an analysis of variance (ANOVA) (SAS) with plant species (whole plot) and flower color (subplot) as the main sources of variation. Data for Expt. 2 were subject to an ANOVA (SAS) with block and plant species as the main sources of variation. Significant means were separated using a Fisher's protected least significant difference (LSD) test at $P \leq 0.05$. All data presented are non-transformed.

\section{Results}

Western flower thrips preference for the different plant species and flower colors was based on the number ofWFT adults collected from each flower.

ЕхРт. 1. The highest numbers of WFT were recovered from the transvaal daisy flowers. There were significant differences in the number of WFT adults collected among the flower colors within each plant species $(F=5.99$; $\mathrm{df}=2,11 ; P=0.0034)$. Significantly more WFT adults were recovered from both the yellow transvaal daisy and yellow chrysanthemum flowers than from the other respective colors (Table 1). Although the highest number of WFT adults was recovered from white matsumoto aster, this number was not significantly different from the other colors (Table 1).

Expt. 2. Plant species were significantly different for the number of WFT adults recovered $(F=21.05 ; \mathrm{df}=$ $3,12 ; P<0.0001)$ with yellow transvaal daisy flowers having significantly higher numbers of WFT adults than the white matsumoto aster and yellow chrysanthemum. In fact, almost twice as many WFT adults were recovered from yellow transvaal daisy flowers than white matsumoto aster and yellow chrysanthemum (Table 2).

Table 1. Mean number of western flower thrips adults recovered from open flowers for the individual plant species and flower colors. A separate analysis was conducted for each plant type.

\begin{tabular}{lllc}
\hline Plant & $n$ & $\begin{array}{c}\text { Flower } \\
\text { color }\end{array}$ & $\begin{array}{c}\text { No. of western flower thrips } \\
\text { recovered }^{\mathbf{z}}\left(\mathbf{m e a n}^{\mathrm{m}} \mathbf{\text { SE}}\right)\end{array}$ \\
\hline Transvaal daisy & 10 & Magenta & $12.4 \pm 2.2 \mathrm{~b}$ \\
Transvaal daisy & 10 & Orange & $22.6 \pm 4.0 \mathrm{~b}$ \\
Transvaal daisy & 10 & Red & $14.5 \pm 3.6 \mathrm{~b}$ \\
Transvaal daisy & 10 & Yellow & $54.4 \pm 7.1 \mathrm{a}$ \\
Matsumoto aster & 10 & Magenta & $13.6 \pm 2.1 \mathrm{a}$ \\
Matsumoto aster & 10 & Pink & $14.3 \pm 2.6 \mathrm{a}$ \\
Matsumoto aster & 10 & Purple & $14.5 \pm 2.5 \mathrm{a}$ \\
Matsumoto aster & 10 & White & $22.7 \pm 3.9 \mathrm{a}$ \\
Chrysanthemum & 10 & Lavender & $11.7 \pm 2.0 \mathrm{~b}$ \\
Chrysanthemum & 10 & Red & $12.2 \pm 2.0 \mathrm{~b}$ \\
Chrysanthemum & 10 & White & $14.1 \pm 1.9 \mathrm{~b}$ \\
Chrysanthemum & 10 & Yellow & $30.2 \pm 4.8 \mathrm{a}$
\end{tabular}

${ }^{2}$ Means, within a plant type, not followed by a common letter for each flower color are significantly different $(P \leq$ 0.05 ) as determined by Fisher's protected least significant difference test. 
Spectral reflectance. The flower colors tested had different spectral reflectance characteristics. The most preferred color and plant species, yellow transvaal daisy, had a reflectance that leveled off at 580 to $600 \mathrm{~nm}$ (green-yellow color) (Fig. 3). Yellow chrysanthemum reflectance began to peak at $500 \mathrm{~nm}$ (blue) and leveled off at $520 \mathrm{~nm}$ (blue-green), whereas white matsumoto aster leveled off at 440 to $450 \mathrm{~nm}$ (violet-blue) (Fig. 3).

Likewise the sticky cards had different reflectance spectra characteristics based on their color (Fig. 4). The blue sticky card had a broad peak between 420 and $480 \mathrm{~nm}$ in the violet-blue portion of the spectrum but also leveled off in the near infrared (about $750 \mathrm{~nm}$ ). The yellow sticky card reflectance plateau began at $520 \mathrm{~nm}$ and peaked at $580 \mathrm{~nm}$ (green-yellow), whereas the yellow, black-lined sticky card reflectance leveled off at a slightly higher wavelength, beginning at 520 $\mathrm{nm}$ and peaking in the yellow-orange portion of the spectrum at 580 to $600 \mathrm{~nm}$ (Fig. 4). The band patterns for yellow transvaal daisy were very similar to those of the yellow sticky cards for all the wavelengths evaluated, but were different from the blue sticky cards (Fig. 4).

\section{Discussion}

Color preference information of WFT is somewhat limited by the fact that only a few studies have actually used flowers to determine flower color preference (Chyzik et al., 1995; Guam and Pringle, 1994; Yudin et al., 1987). The appearance of color is a complex phenomenon, which depends on a particular combination of reflected wavelengths and on other physical characteristics of a given surface (Hunter and Harold, 1987). Additionally, flower petal surfaces are quite different from sticky or other paper card surfaces, which are not necessarily directly comparable. Comparisons are even more difficult without knowing the spectral reflectance of the surfaces, and no spectral information regarding colored surfaces or illumination of the environment has been reported in previous studies on color preference. Another limitation of previous studies is the fact that most were conducted in relatively uncontrolled conditions and used existing WFT populations either in the field or greenhouse.

In our study, however, we used
Table 2. Mean number of western flower thrips adults recovered from the open flowers of each plant species and a plastic white flower.

\begin{tabular}{llcc}
\hline Plant & $n$ & $\begin{array}{c}\text { Flower } \\
\text { color }\end{array}$ & $\begin{array}{c}\text { No. of western flower thrips } \\
\text { recovered }^{\mathbf{2}}\left(\mathbf{m e a n}^{ \pm} \mathrm{SE}\right)\end{array}$ \\
\hline Transvaal daisy & 10 & Yellow & $43.2 \pm 8.1 \mathrm{a}$ \\
Chrysanthemum & 10 & Yellow & $21.8 \pm 3.4 \mathrm{~b}$ \\
Matsumoto aster & 10 & White & $24.0 \pm 6.2 \mathrm{~b}$ \\
Plastic flower & 10 & White & $0.9 \pm 0.4 \mathrm{c}$ \\
\hline
\end{tabular}

${ }^{2}$ Means not followed by a common letter are significantly different $(P \leq 0.05)$ as determined by Fisher's protected least significant difference test.

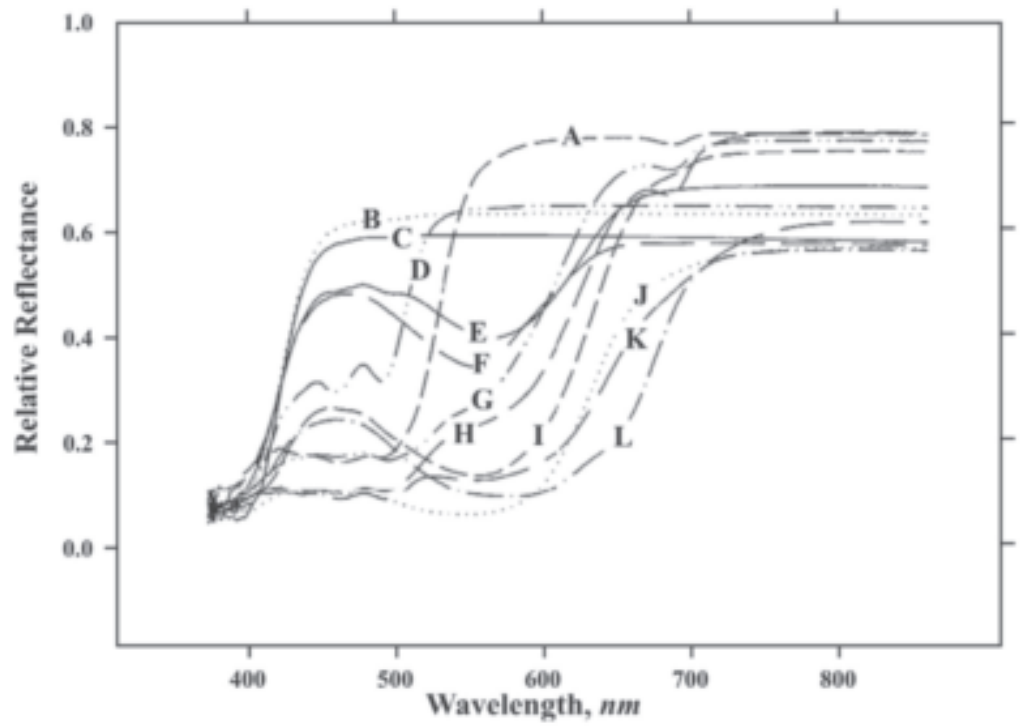

Fig. 3. Spectral reflectance for flower petals of all plant species and flower color combinations. $A$ = yellow transvaal daisy, $B=$ white chrysanthemum, $C=$ white matsumoto aster, $\mathrm{D}=$ yellow chrysanthemum, $\mathrm{E}=$ lavender chrysanthemum, $\mathrm{F}$ = pink matsumoto aster, $\mathrm{G}=$ orange transvaal daisy, $\mathrm{H}=\operatorname{red}$ transvaal daisy, $\mathrm{I}=$ magenta transvaal daisy, $\mathrm{J}=$ magenta matsumoto aster, $\mathrm{K}=$ burgundy chrysanthemum, $\mathrm{L}=$ purple matsumoto aster.

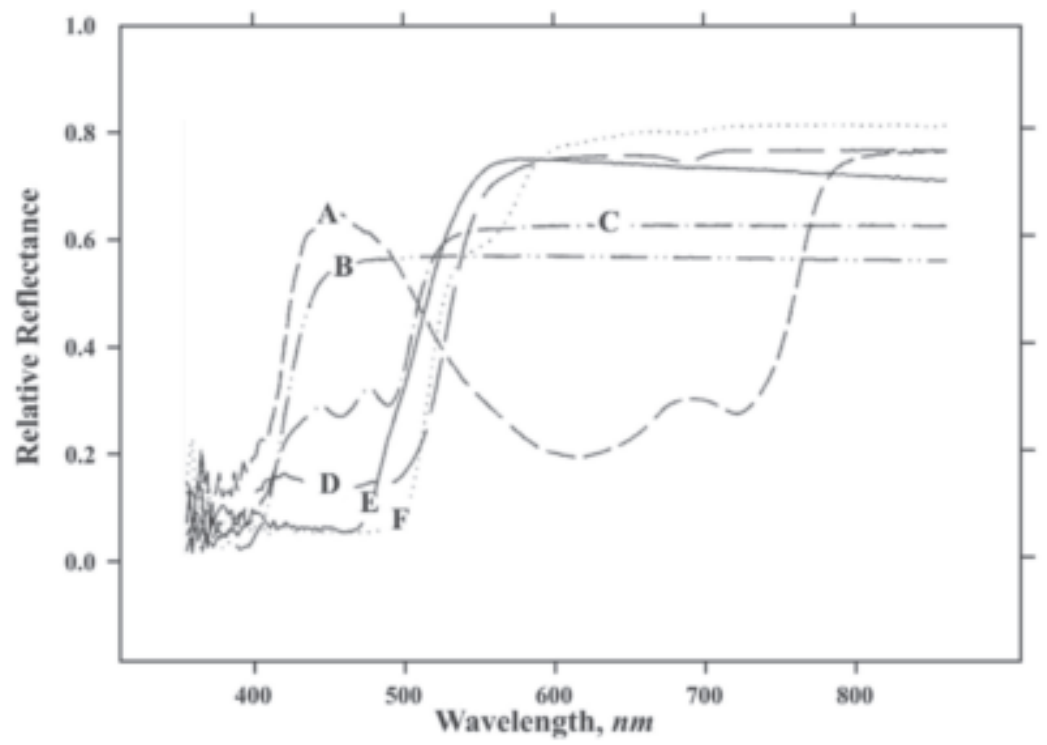

Fig. 4. Spectral reflectance for three commercially available sticky cards (blue and two types of yellow) compared to that of the three preferred flowers determined from Expt. 1. A = blue sticky card, B = white matsumoto aster, $\mathrm{C}=$ yellow chrysanthemum, $\mathrm{D}=$ yellow sticky card, $\mathrm{E}=$ yellow transvaal daisy, and $\mathrm{F}=$ yellow / black-lined sticky card. 
live plants with different-colored flowers and WFT populations enclosed in chambers to collect more direct information on WFT flower color preference, thus reducing the variability encountered under field and greenhouse conditions. The use of chambers in controlled environmental facilities minimized problems associated with natural conditions and thereby the possible bias associated with WFT adults' relatively weak flying abilities (Hollister et al., 1995). In addition, the spectral reflectance of the flowers was determined to allow comparison with the reflectance spectrum of three colored sticky cards. Spectral properties of the environment, primarily illumination, were also measured to ensure sufficient radiation was provided in the specific wave bands identified as being attractive. All this information will make it possible to obtain more direct and accurate assessments for selecting trap crops or in developing more effective sticky cards.

In this study, significant differences were observed among the different flower genera and colors. Within the different genera, yellow transvaal and yellow chrysanthemum appeared to be the most preferred colors (Table 1). Almost twice as many WFT were collected from the yellow transvaal daisy than from either the yellow chrysanthemum or white matsumoto aster in Expt. 2 when the flowers having the highest number ofWFT from the three genera were compared directly (Table 2 ). When the petal reflection spectra are compared among the different genera and colors (Fig. 3), the yellow transvaal daisy displays a small reflectance in the bandwidth of 420 to $500 \mathrm{~nm}$ and then increases three-fold in the 540 to 580 $\mathrm{nm}$ bandwidth, remaining at a constant maximum throughout the rest of the measured range (Fig. 3). The flower appears yellow to humans because our visual sensitivity is lacking in both the low (blue) and high (red) portions of the measured spectrum and reaches a maximum at approximately 580 to $600 \mathrm{~nm}$ (green-yellow) (Hunter and Harold, 1987). The relatively high red reflectance gives the flower an overall yellow color appearance, which may be more visible to WFT. Insects, in general, tend to be attracted to the ultraviolet portions of the color spectrum (Menzel 1975) as this may indicate the presence of a food source such as pollen or nectar. Although the yellow chrysanthemum appeared to be similar in color as the yellow transvaal daisy, the yellow chrysanthemum had a significantly different reflectance spectrum with approximately twice the reflectance in the blue as the yellow transvaal daisy, reaching a reflectance peak at 500 and $540 \mathrm{~nm}$ and remaining constant to $850 \mathrm{~nm}$ (Fig. 3). It is possible that the higheryellow transvaal daisy reflectance in the yellow and red portion of the spectrum resulted in this flower color appearing brighter to the WFT and thus more visible, and therefore the preferred flower. This would certainly be the case if WFT has the same visual response as humans, and supports the findings of Guam and Pringle (1994), who demonstrated that WFT tend to prefer yellow roses to other colors. The white matsumoto aster was just as attractive to WFT as the yellow chrysanthemum; however, the reflectance was quite different in that the maximum peak, which was slightly less than that of the yellow chrysanthemum, occurred around 450 $\mathrm{nm}$ and remained constant throughout the measured range.

It appears that the shorter wavelengths, in the 380- to $450-\mathrm{nm}$ bandwidth, are less attractive to WFT, which contradicts the notion that blue sticky cards are more effective for either sampling or trapping WFT. White chrysanthemum has a similar reflectance spectrum to the white matsumoto aster, but was apparently less attractive to the WFT, although no direct comparisons between the

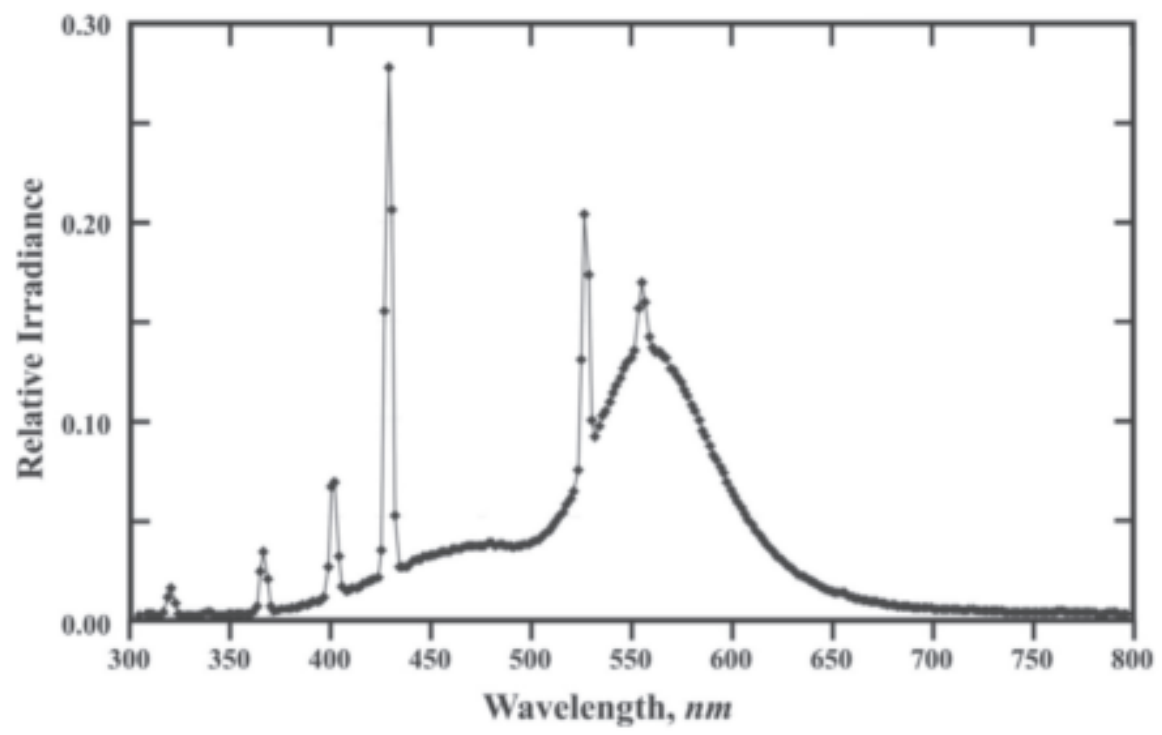

Fig. 5. Spectral emission of the cool white fluorescent lamps illuminating the chambers used in the study. two were made, indicating that some other factor may be more important in chrysanthemum. Unfortunately, there were no yellow matsumoto asters available during this study for comparison to the white matsumoto aster. Based on the numbers of WFT collected from flowers with peak reflectance spectrum values in the 550 - to $600-\mathrm{nm}$ bandwidth range, this may be the most attractive bandwidth to WFT. Again, if WFT have the same visual response as humans, then these flower colors would not be as bright and therefore may not be as attractive.

When the flower spectra are compared to the spectrum of the sticky cards (Fig. 4), both yellow sticky cards have similar spectra to the yellow transvaal daisy, which substantiates the use of yellow sticky cards in scouting programs for WFT (Heinz et al., 1992; Shipp and Zariffa, 1991) or mass-trapping at low densities (Kawai and Kitamura, 1987). Additionally, yellow sticky cards have also proven useful for sampling or trapping greenhouse whitefly and the vegetable leafminer (Affeldt et al., 1983). However, the blue sticky card, which is considered more effective for sampling or trapping WFT (Brodsgaard, 1989; Frey, 1993; Vernon and Gillespie, 1990), has a reflectance spectrum more similar to the lavender, magenta, pink, purple, and burgundy flowers, which were apparently the least attractive colors to WFT. The reason for this contradictory response may be due to the radiation spectrum provided by the fluorescent lamps (Fig. 5), which 
provides significantly more irradiance in the green-yellow wavelengths ( 500 to $600 \mathrm{~nm}$ ) than the violet-blue wavelengths (350 to $450 \mathrm{~nm}$ ), and would therefore make green-yellow appear relatively brighter or more visible to the WFT than blue. Radiation sources such as solar, metal halide, and HID emit a higher proportion of violetblue wavelengths, indicating that blue cards or flowers may be more effective in attracting WFT when they are the primary source.

The premise of this research was to initially identify potential trap crops for WFT and assess the impact of spectral reflectance qualities of flowers on insect attractiveness, which would provide information that is lacking in the scientific literature. By no means is this the only important aspect of identifying trap crops, but it is a legitimate initial step because the testing of artificial surfaces with various spectral properties and WFT has been extensively studied. This research, although limited in scope, does present information on three plant species and flower colors within each species, which may be helpful in assessing flowers that have potential as trap crops for WFT. In this study we only quantified flower color, as it was not possible, based on the experimental design, to separate out confounding factors such as flower volatiles (or exudates) and pollen availability. The presence of any floral volatiles emitted from the flowers tested, particularly among the different genera and flower colors, may have influenced the results by inadvertently attracting more adult WFT, thus negating the effects of color. Also, the number of flowers used (three chrysanthemums, five matsumoto asters, and one transvaal daisy) may have influenced the amount of volatiles emitted. In order to remove the effects of flower volatiles it would have been necessary to either filter the air or, if possible, remove the volatileproducing glands from the flowers. However, flower volatiles, depending on the plant species, may not always be attractive to WFT. For example, floral volatiles from certain rose cultivars do not necessarily attract higher numbers of WFT (Guam et al., 1994).

In our study, color spectral reflectance was quantified, which can be used to assess the results established in other studies. Additionally, in determining a trap crop for WFT, the effects of floral volatiles and pollen shed are important factors that should be studied because any trap crop may be attractive to WFT based on either flower color, flower volatiles, and pollen age, or a combination of these factors.

In conclusion, our results have provided useful insight into the color preference of WFT and are an initial step that will assist researchers in attempting to identify potential trap crops for WFT. The technique we have developed for determining flower color preference will help to further advance the research designed to study WFT preferences and behavior, which will be important in developing trap crops and more effective sticky cards for WFT, leading to improved scouting techniques for greenhouse producers. Based on our results, yellow transvaal daisy may be a useful trap crop to assist greenhouse producers in managing WFT.

\section{Literature cited}

Affeldt, H.A., R.W. Thimijan, F.F. Smith, and R.E. Webb. 1983. Response of the greenhouse whitefly (Homoptera: Aleyrodidae) and the vegetable leafminer (Diptera: Agromyzidae) to photospectra. J. Econ. Entomol. 76(6):1405-1409.

Allen, W.R. and A.B. Broadbent. 1986. Transmission of tomato spotted wilt virus in Ontario greenhouses by Frankliniella occidentalis. Can. J. Plant Pathol. 8:33-38

Bennsion, J.A., E.M. Pow, L.J. Wadhams, K.A. Maulden, L.R. Wardlow, and J.H. Buxton. 1999. Improving biological control of western flower thrips, Frankliniella occidentalis, on greenhouse ornamentals. Proc. 6th Intl. Symp. Thysanoptera, Akdeniz Univ., Antalya, Turkey. p. 19-24.

Biondo, R.J. and D.A. Noland. 2000. Floriculture: From greenhouse production to floral design. Interstate Publ., Danville, Ill.

Brodsgaard, H.F. 1989. Coloured sticky traps for Frankliniella occidentalis (Pergande) (Thysanoptera, Thripidae) in glasshouses. J. Appl. Entomol. 107:136-140.

Chandler, L.D. 1981. Evaluation of different shapes and color intensities of yellow traps for use in population monitoring of dipterous leaf miners. Southwestern Entomol. 6(1):23-27.

Chang-Chi, C., P. Pinter Jr., T. Henneberry, K. Umeda, E. Natwick, W. Yaun-an, V. Reddy, and M. Shrepatis. 2000. Use of CC traps with different trap base colors for silverleaf whiteflies (Homoptera:Aleyrodidae), thrips (Thysanoptera:Thripidae), and leafhoppers (Homoptera: Cicadellidae). J. Econ. Entomol. 93:1329-1337.

Cho, K., C.S. Eckel, J.F. Walgenbach, and G.G. Kennedy. 1995. Comparison of colored sticky traps for monitoring thrips populations (Thysanoptera: Thripidae) in staked tomato fields. J. Entomol. Sci. 30:176-190.

Chyzik, R., M. Klein, Y. Ben Dov, and A. Cohen. 1995. Differential population density of western flower thrips in various flower colors in gladiolus, p. 449-452. In: Parker, D., M. Skinner, and T. Lewis (eds.), Thrips biology and management, Plenum Press, New York.

Cloyd, R.A., D.F. Warnock, and K. Holmes. 2001. Technique for collecting thrips for use in insecticide efficacy trials. HortScience 36:925-926.

Cohen, J.B. 1988. Color and color mixture: Scalar and vector fundamentals. Color 13(1):5-39.

Daughtrey, M.L., R.K. Jones, J.W. Moyer, M.E. Daub, and J.R. Baker. 1997. Tospoviruses strike the greenhouse industry. Plant Dis. 81(11):1220-1230.

DeAngelis, J.D., D.M. Sether, and P.A. Rossingnol. 1994. Transmission of impatiens necrotic spot virus in peppermint by western flower thrips (Thysanoptera: Thripidae). J. Econ. Entomol. 90:679-688.

Frey, J.E. 1993. Damage threshold levels for western flower thrips, Frankliniella occidentalis (Perg.) (Thysanoptera: Thripidae) on ornamentals. Intl. Org. Biolog. Integrated Control/Western Palaearctic Reg. Section Bul. 16:78-81.

Gillespie, D.R. and R.S. Vernon. 1990. Trap catch of western flower thrips (Thysanoptera: Thripidae) as affected by color and height of sticky traps in mature greenhouse cucumber crops. J. Econ. Entomol. 83:971-975.

Gross, H.R. and J.E. Carpenter. 1991. Role of the fall armyworm (Lepidoptera: Noctuidae) pheromone and other factors in the capture of bumblebees (Hymenoptera: Aphidae) by universal moth trap. Environ. Entomol. 20:377-381.

Guam, W.G. and J.H. Pringle. 1994. Resistance of some rose cultivars to the western flower thrips, Frankliniella occidentalis (Thysanoptera: Thripidae). Bul. Entomol. Res. 84:487-492.

Guam,W.G., Giliomee, J.H., and K.L. Pringle. 1994. Resistance of some rose cultivars to the western flower thrips, Frankliniella occidentalis (Thysanoptera: Thripidae). Bul. Entomol. Res. 84:487-492.

Heinz, K.M., M.P. Parrella, and J.P. Newman. 1992. Time-efficient use of yellow 
sticky cards in monitoring insect populations. J. Econ. Entomol. 85:2263-2269.

Higgins, C.J. 1992. Western flower thrips (Thysanoptera: Thripidae) in greenhouses: Population dynamics, distribution on plants, and associations with predators. J. Econ. Entomol. 85:1891-1903.

Hokkanen, H. 1991. Trap cropping in pest management. Ann. Rev. Entomol. 36:119-138.

Hollister, B., E.A. Cameron, and D.A.J. Teulon. 1995. Effect of $p$-anisaldehyde and a yellow color on behavior and capture of western flower thrips, p. 571-574. In: B.L. Parker, M. Skinner, and T. Lewis (eds.). Thrips biology and management. Plenum Press, New York.

Hooper, A.M., J.A. Bennison, M.C. Lusnials, J.A. Pickett, E.M. Pow, and L.J. Wadhams. 1999. Verbena $\times$ bybrida flower volatiles attractive to western flower thrips, Frankliniella occidentalis. Pest Sci. 55:660-662.

Hunter, R.S. and R.W. Harold. 1987. The measurement of appearance. Wiley, New York.

Hunter, W.B. and D.E. Ullman. 1992. Anatomy and ultrastructure of the piercing-sucking mouthparts and paraglossal sensilla of Frankliniella occidentalis (Pergande) (Thysanoptera: Thripidae). Intl. J. Insect Morphol. Embryol. 21:17-35.

Immaraju, J.A., T.D. Paine, J.A. Bethke, K.L. Robb, and J.P. Newman. 1992. Western flower thrips (Thysanoptera: Thripidae) resistance to insecticides in coastal California greenhouses. J. Econ. Entomol. 85:9-14.

Jacobson, R.J. 1995. Resources to implement biological control in greenhouses, $\mathrm{p}$. 211-219. In: B.L. Parker, M. Skinner, and T. Lewis (eds.). Thrips biology and management. Plenum Press, New York.

Jan de Kogel, W., M. van der Hoek, M.T.A. Dik, F.R. van Dijken, and C. Mollema. 1998. Variation in performance of western flower thrips populations on a susceptible and a partially resistant chrysanthemum cultivar. Euphytica 103:181-186.

Javaid, I. and J.M. Joshi. 1995. Trap cropping in insect pest management. J. Sustainable Agr. 5:117-136.

Kawai, A. and C. Kitamura. 1987. Studies on population ecology of Thrips palmi
Karny. XV. Evaluation of effectiveness of control methods using a simulation model. Appl. Entomol. Zool. 22:292-302.

Kirk, W.D.J. 1997. Distribution, abundance, and population dynamics, p. 217-257. In: T.

Lewis (ed.). Thrips as crop pests. CAB Intl., Wallingford, U.K.

Lloyd, L. 1921. Notes on colour tropism of Asterochiton (Aleurodes) vaporariorum Westwood. Bul. Entomol. Res. London 12:355-359.

Loughner, R.L., D.F. Warnock, and R.A. Cloyd. 2005. Resistance of greenhouse, laboratory, and native populations of western flower thrips to spinosad. HortScience 40(1):146-149.

MacDowell, F.D.H. 1972. Phototactic action spectrum for whitefly and the question of color vision. Can. Entomol. 104:299-307.

Mateus, C. and A. Mexia. 1995. Western flower thrips response to color, p. 567-570. In: B.L. Parker, M. Skinner, and T. Lewis (eds.). Thrips biology and management. Plenum Press, New York.

Matteson, N., I. Terry, A. Ascoli-Christensen, and C. Gilbert. 1992. Spectral efficiency of the western flower thrips, Frankliniella occidentalis. J. Insect Physiol. 38:453-459.

Menzel, R. 1975. Colour receptors in insects, p. 121-154. In: G.A. Horridge (ed.). The compound eye and vision in insects. Oxford Univ. Press, London, U.K.

Mills, N.J. and K.M. Daane. 2005. Biological and cultural control: Nonpesticide alternatives can suppress crop pests. Calif. Agr. 59(1):23-28.

Moffitt, H.R. 1964. A color preference of the western flower thrips, Frankliniella occidentalis. J. Econ. Entomol. 57:604-605.

Mound, L.A. 1962. Studies on the olfaction and colour sensitivity of Bemisia tabaci(Genn.) (Homoptera: Aleyrodidae). Entomol. Expt. Appl. 5:99-104.

Parrella, M.P. 1995. IPM-Approaches and prospects, p. 357-363. In: B.L. Parker, M. Skinner, and T. Lewis (eds.). Thrips biology and management. Plenum Press, New York.
Pearsall, I.A. and J.H. Meyers. 2000. Evaluations of sampling methodology for determining the phenology, relative density, and dispersion of western flower thrips (Thysanoptera: Thripidae) in nectarine orchards. J. Econ. Entomol. 93:494-502.

Shipp, J.L. and N. Zariffa. 1991. Spatial patterns of and sampling methods for western flower thrips (Thysanoptera: Thripidae) on greenhouse sweet pepper. Can. Entomol. 123:989-1000.

Steel, R.G.D., J.H. Torrie, and D.A. Dickey. 1997. Principles and procedures of statistics: A biometrical approach. 2nd ed. McGraw-Hill, New York.

Suderland, K.D., R.J. Chambers, N.L. Helyer, and P.I. Sopp. 1992. Integrated pest management of greenhouse crops in northern Europe. Hort. Rev. 13:1-66.

Terry, L.I. 1997. Host selection, communication and reproductive behavior, $p$. 65-118. In: T. Lewis (ed.). Thrips as crop pests. CAB Intl., Wallingford, U.K.

Teulon, D.A.J., D.R. Penman, and P.M.J. Rammakers. 1993. Volatile chemicals for thrips (Thysanoptera: Thripidae) host-finding and applications for thrips management. J. Econ. Entomol. 86:1405-1415.

Tyron, E.H., Jr., S.L. Poe, and H.L. Cromroy. 1980. Dispersal of vegetable leafminer onto a transplant production range. Fla. Entomol. 63(3):292-296.

Vernon, R.S. and D.R. Gillespie. 1995. Influence of trap shape, size, and background color on captures of Frankliniella occidentalis (Thysanoptera: Thripidae) in a cucumber greenhouse. J. Econ. Entomol. $88: 288-293$.

Vernon, R.S. and D.R. Gillespie. 1990. Spectral responsiveness of Frankliniella occidentalis (Thysanoptera: Thripidae) determined by trap catches in greenhouses. Environ. Entomol. 19:1229-1241.

Walker, W.F. 1974. Responses of selected Thysanoptera to colored surfaces. Environ. Entomol. 3:295-304.

Yudin, L.S., W.C. Mitchell, and J.J. Cho. 1987. Color preference of thrips (Thysanoptera: Thripidae) with reference to aphids (Homoptera: Aphidae) and leaf miners in Hawaiian lettuce farms. J. Econ. Entomol. 80:51-55. 